\section{A segunda república}

Por Edgard Carone. São Paulo, Difusão Européia do Livro, 1973.

Reunindo uma coleção de textos básicos e documentos, a recente publicação de A segunda república (1930 a 1937) é continuação do trabalho anterior do autor, A primeira república (1889 a 1930), e como resposta concreta surge um guia de orientação àqueles que pretendem conhecer melhor o perlodo.

$\mathrm{Na}$ introdução, Edgard Carone diz que a época republicana, não obstante dispor de uma documentação bastante vasta, não tem sido suficientemente analisada; é enfocada quase sempre de maneira simplista, unila126 teral e portanto distorcida:

"O prático desconhecimento dos fatos entre 1930-1937, para não dizer 1930-1945, faz com que os estudiosos - economistas, sociólogos e historiadores - prefiram 'englobar' suas opiniōes, tornando-as genéricas, o que os leva a afirmar que a indústria brasileira nasce com a revolução de 1930'; 1930 assinala 'o predomínio da indústria sobre a agricultura'; o 'getulismo é força principal em todo este período' etc. Estes conceitos vagos confundem os problemas, pois neste momento de transição as questões são complexas e exigem análise acurada, no geral e no particular." (p. 5.)

A obra analisada coloca à nossa disposição uma série de documentos que, poderíamos dizer, "falam por si", no sentido de se contrapor a muito do que tem sido escrito até o presente. A forma como os textos estão organizados parece constituir-se em instrumento de advertência aos pesquisadores, na medida em que, ao Ihes apontar concretamente a complexidade do período, exige-lhes maior reflexão e uma nova atitude.

E evidente que o simples basear neste tipo de trabalho não leva a uma atitude cientifica, pois os fatos falam, mas não se explicam.

O nivel de objetividade depende muito dos pontos de referências adotados pelo investigador. Contudo, somente a partir de uma criteriosa seleção - e esta parece não deixar dúvidas - é possivel extrair um nivel objetivo de explicação das relações entre os fenômenos.

Uma crítica comum que se faz a livros de textos é que eles devem conter apenas textos, que interpretações à base de "introdução", "notas de rodapé" ou "elementos explicativos" ferem os pressupostos de objetividade desse tipo de publicação. Discordamos: a) por perceber que a interpretação já está contida na escolha e até na delimitação dos trechos dos documentos; b) interpretaçöes não significam necessariamente ausência de rigor e de objetividade científica. Trata-se de uma visão antiga decorrente de comparações entre ciências humanas e exatas, em que se acentuava a eliminação da subjetividade pessoal. A vi- são moderna aćentua a impor. tância de tal subjetividade como ponto de estratégia para o conhecimento; c) a validade científica da utilização de seletas, como de qualquer outra obra, está num tipo de relação entre o pesquisador e o elemento estudado. Ao se extrair uma explicação das relações entre os fenômenos, com base nos documentos, devese ter em conta a própria posição do autor da seleta. Cabe ainda analisá-lo como produto de uma situação social concreta, qual o seu ponto de partida e quais os critérios adotados.

A obra de Edgard Carone é elaborada em três partes: Sistema político, Economia e Classes sociais, sendo esta última a mais extensa de todas e vista somente através de suas formas ideológicas.

$\mathrm{Na}$ introdução, o próprio autor traça o desenvolvimento e rela. ções dessas partes, ponderando sempre que as mesmas não es. gotam o período.

Cada texto é epigrafado com uma sintese explicativa que serve de quadro de referência ao leitor. Finaliza o livro uma parte de notas, em que é feita uma breve apresentação dos textos, e o autor dá-nos conta das fontes de onde retirou os originais. Aqui, justamente por reconhecermos que alguns textos são de difícil acesso, pensamos que a obra seria mais completa se contivesse uma indicação pormenorizada dos locais onde os textos podem ser encontrados.

Destacamos como ponto de nosso maior interesse, a parte referente às classes sociais, por se encontrarem bastante diversjficadas nesta fase e expressarem a dinâmica do periodo, aqueles fenômenos de aproximação e distanciamento entre as camadas e grupos no espaço social. 
A proposição do autor é estudar essas camadas, segmentos que estão sendo formados em suas manifestações conjuntas. Isto porque apesar das alterações, ainda existe identificação entre os setores agrários e urbanos, ambos partilhando uma origem comum. A queda das veIhas oligarquias não são seguidas automaticamente pelo dominio de uma nova. Uma comprovação é o ressurgimento do Partido Republicano Paulista, que assinala a presença do partido em 1932.

"O Partido Republicano Paulista, que só na vontade popular tem procurado o norte das suas diretrizes, sente-se no dever de quebrar, hoje, o deliberado silêncio a que se recolhera, para definir com precisão a sua atitude neste decisivo momento da vida nacional. E pelo regime constitucional. E pelo regime republicano. E pelo regime federativo...

... Volta ele, assim, após tantos meses de voluntário retraimento, ao exercício normal dos seus deveres civicos, que nunca desamparou... Reenceta, pois, a sua atividade como o começou, há mais de sessenta anos, isto é, batalhando com denodo pela democracia e pela República, sem prejuizo da união, da concórdia e da paz entre todos os brasileiros". (p. 196.)

Por outro lado, a formação da Liga Eleitoral Católica (1933), do Centro Dom Vital e de outras organizações indica a forma do emergir político da Igreja. Carta pastoral de 25.12.1931 transmite a posição política dessa instituição, ao opinar sobre os três males que afligiam o País: o enfraquecimento do princípio de autoridade, a. carência de lei - constitucional e a infiltração comunista. Mesmo na prática, sua atuação permanece crítica.
"Podemos, pois, recapitular e concluir que o Brasil é hoje um país, onde, combalido o princípio de autoridade, mais domina a força que o direito; um país sem constituição, que, entregue ao poder discricionário dos seus governantes, pode facilmente descambar para o absolutismo; um país, enfim, que depauperado na sua economia, acha-se francamente exposto à invasão deletéria do bolchevismo e da anarquia". (p. 204.)

No documento sobre "A questẫo social no Brasil" vemos como o tema é encarado na época, indicando-nos a postura dos representantes do comércio e indústria:

"Não há classes sociais no Brasil. Os operários de ontem são os chefes de indústrias de hoje. $\mathrm{Na}$ Europa o indivíduo nasce operário e morre operário. No Brasil, se ele for ativo, inteligente e previdente consegue uma posição abastada. Na Europa há luta de classes. No Brasil não existe..."

"O que nós temos no Brasil é um melting pot, um vasto cadinho em que tudo está em fusão e transformação permanentes, em que ninguém sabe o que vai resultar desta ampla fermentação, que é o progresso intenso e que nos vai dar uma civilização grande como a americana, mas de tendências raciais, sociais e intelectuais muito diferentes. Talvez venhamos a ter a raça cósmica, isto é, fruto da combinação de todas as raças que habitam o universo." (p. 208-9.)

Dois outros textos, o discurso de Armando Salles de Oliveira, em São José do Rio Pardo e o manifesto da União Democrática Brasileira, revelam num só tempo a fermentação do momento histórico e as possíveis direções desse processo. Tentativas de conciliações de dois pares antitéticos: federalismo $e$ maior poder do executivo ou federalismo com modelos fascistas. Parece diretamente proporcional: quanto mais se falam dos problemas típicos e característicos brasileiros que devem ser tratados dentro de suas fronteiras, mais aparecem soluções nos programas de partidos apoiados em modelos externos:

"Os sentimentos regionais não são manifestações de orgulho dos Estados mais ricos: existem com igual vigor em todos os pequenos Estados. Não constitui rivalidades que enfraqueçam, mas saudáveis emulações que robusteçam a nação. Além disso, todos sentem as vantagens do sistema descentralizado que, pondo o poder público em contato direto com as necessidades coletivas, dá maior eficácia à administração, simplificando-a e nela introduz todas as gradua. ções da hierarquia, a disciplina, a competência e a responsabilidade...

Dando um concurso decisivo para a instituição da República e proclamando-a sob a forma federativa, o nosso Exército, principal instrumento da unidade nacional, também reconheceu que unidade e federação, no Brasil, sāo idéias inseparáveis...

Mais uma vez afirmo a minha convicção de que o regime presidencial é o mais adequado para - nosso país. Por meio dele se conciliam o Estado forte e a organização democrática.

A lembrança dos abusos do passado e do funcionamento vicioso do antigo regime deixa hesitantes muitos espiritos sempre que se fala em dar ao executivo novas atribuições que the permita reagir com vigor contra os ataques extremistas..."

Vejamos ainda:

"Nós não necessitamos coIher na panóplia internacional a arma mais eficaz para o comba- 
te contra as investidas bolchevistas. Se cometêssemos o erro de apelar para o regime totalitário, não apagaríamos as esperanças das ambições comunistas que espreitam o Brasil. A centralização traz o germe da morte inevitável: atirando o país, mais cedo ou mais tarde, na guerra civil, conduziria à desagregação. . .

...Peçamos à Itália, à Alemanha e a Portugal os poderosos métodos de propaganda por meio dos quais levaremos aos últimos recantos do país a palavra de união e de fé em volta da bandeira da Pátria. Imitemos dessas admiráveis nações a exaltação patriótica, o espírito de renúncia, a força de organização, a capacidade renovadora. Conservemos, porém, a nossa roupa, permaneçamos brasileiros..." ( $p$. 213-15.)

Enquanto Armando Salles de Oliveira prepara a sua candidatura presidencial, Getulio Vargas, os integralistas e parte da burguesia articulam o futuro golpe de estado de 10 de novembro de 1937.

Os 80 documentos apurados em A segunda república são, a nosso ver, indispensáveis a tantos quantos desejem saber de nossa história contemporânea. Isto porque permitem-nos chegar às raízes de determinados problemas persistentes até nossos dias, com seus efeitos multipli128 cadores.

Ao nível da pesquisa também torna-se úma obra de leitura obrigàtória, à medida que sugere a possibilidade de um exame mais profundo e de uma tomada de consciência mais ampla das interconexões - entre as situações e as idéias - tais quais são propostas na própria divisão do livro: Sistema político, Economia e Classes sociais em suas configurações ideológicas.

Cleide de Oliveira Vilão
A short history of technology

Por T. K. Derry e Trevor I. Williams. London, Oxford, New York, Oxford University Press, 1960-1973, XVIII, 782 p. Tabelas históricas, bibliografia e índice de assuntos completo, índice de nomes. Ilustrado com 353 gravuras. Brochura $£ 1,90$. Existe encadernado originalmente.

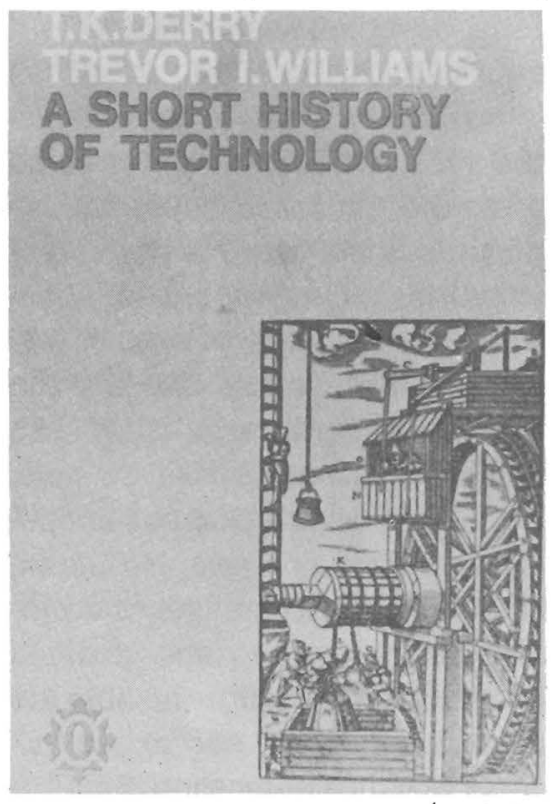

Os conhecimentos de administração de empresas precisam ser atualmente estendidos a áreas periféricas, para que a perspectiva global possa ser mantida. Assim, a área de tecnologia teve seus altos e baixos no ensino e na execução da administração. Ela predominava nas épocas de Taylor até possivelmente a II Guerra Mundial, sendo relegada a um segundo plano pela administração financeira, mercadológica e humano-humanística nas décadas de 50 e 60. A década de 70 trouxe-a de volta, na necessidade de proteção das fon. tes de energia, na urgência da melhoria do trabalho humano no ambiente, na necessidade de conservação do equilíbrio ecológico, e na importância de se estudar o seu inter-relacionamento com o governo e os processos de criatividade. O seu campo foi levado ao estudo de novos produtos e o nacionalismo sadio invadiu os laboratórios de pesquisa. Sem deixar de lado os campos administrativos, financeiros, mercadológicos e humanos, a empresa de hoje tem obrigação de se definir por uma mistura de tecnologia nacional e importada para poder acompanhar a luta pela exportação e a satisfação simultânea de um mercado interno em expansão que agora, em meados de 1973, dá sinais renovados de falta de mão-de-obra especializada.

O livro de Derry e Williams é de leitura agradabilíssima. Tra. ta-se de um resumo da obra de cinco volumes, History of technology, da Imperial Chemical In. dustries da Inglaterra, publicado a partir de 1949 pela Editora Clarendon Press de Oxford. Também este volume ora publicado teve o auxílio financeiro da Imperial Chemical Industries. 0 livro trata resumidamente da história da tecnologia desde o seu começo com o homem pré-histórico, terminando em 1900; so. mente a China e o Japão esca. pam ao estudo, devido à sua re. lativa inacessibilidade às pesqui. sas "ocidentais" estabelecida pe las dificuldades de língua.

O livro termina em 1900 por dois motivos: a) o significado histórico do desenvolvimento de 1900 até hoje é dificilmente ve. rificável num prazo tão curto; b) é quase impossível, num livro dessa extensão (um volume), explicar o desenvolvimento do século $X X$, de indústrias comple. xas com tecnologia de difícil des. crição.

É evidente que pode ser feita objeção aos dois argumentos, porquanto evitar avaliar o significado histórico da energia atô. mica ou do desenvolvimento da aviação é vergonhosa covardia, 